\title{
Disseminated intravascular coagulation in association with congenital neuroblastoma
}

\author{
EILEEN N. THOMPSON* \\ M.D., F.R.C.P., D.C.H. \\ Alan Bosley \\ M.B., B.S., M.R.C.P., D.C.H. \\ Department of Child Health, Welsh National School of Medicine, Llandough Hospital, Cardiff
}

\begin{abstract}
Summary
A 3-month-old infant with neuroblastoma complicated by progressive depletion of coagulation factors and a microangiopathic haemolytic anaemia is described. Specific anti-tumour therapy corrected the haemorrhagic defect on 2 occasions, but did not affect tumour bulk significantly, although a fall in urinary vanillyl-mandelic acid was seen. The rarity of this association and the possible underlying mechanisms are discussed.
\end{abstract}

\section{Introduction}

Neuroblastoma is a common solid tumour of childhood, exceeded only in frequency by brain tumours. The varied clinical course is well known with often spontaneous regression of localized or disseminated tumour in young infants, with or without therapy. Prognosis is often best in infants less than one year of age and for the child with 4S disease (Evans, d'Angio and Randolph, 1971), namely wide dissemination to liver, bone marrow and/or skin but no skeletal involvement. However, despite a large literature on this neoplasm there have only been 2 recorded cases of disseminated intravascular coagulation (DIC) occurring in conjunction with this tumour (McMillan, Gaundry and Holemans, 1968; Faxelius et al., 1975). In both instances the infants were very young ( 3 days and 10 weeks) both had Stage 4S disease and both had the primary lesion in the right adrenal with metastases to the liver, marrow and the other adrenal. The authors have recently had a similar case of Stage 4 neuroblastoma in a young infant with good evidence of microangiopathic haemolytic anaemia and disseminated intravascular coagulation, which responded well initially to cytotoxic chemotherapy with improvement in the coagulation defect and some regression of the tumour mass. However, the improvement was not maintained with recurrence of the tumour and of the haematological abnor-

\footnotetext{
*Requests for reprints.
}

mality. In view of the rarity of this association it is felt that this case is worth reporting.

\section{Case report}

A 7-week-old male infant was referred with a 2-week history of food refusal, irritability and rapidly enlarging abdominal distention. Examination revealed a wasted infant with widespread petechial haemorrhages, bilateral peri-orbital haematomata, skin nodules, abdominal distension due to hepatomegaly and a right-sided abdominal mass. He was not jaundiced but was anaemic with prolonged bleeding from venepuncture sites. Intravenous pyelograph showed a right-sided calcified suprarenal mass displacing the kidney downwards. Skeletal survey was normal, but bone scan showed increased uptake in the frontal region of the skull and peri-orbital region. Liver scan showed multiple hepatic deposits. Bone marrow showed marked normoblastic hyperplasia with many clumps of malignant cells considered to be secondary deposits from a neuroblastoma. Numerous megakaryocytes were present. Urinary vanillyl-mandelic acid (VMA) levels were 151 and $154 \mathrm{mmol} / \mathrm{mol}$ of creatinine (normal $<20 \mathrm{mmol} / \mathrm{mol}$ creatinine). The presence of microangiopathic haemolytic anaemia and the consumption coagulopathy (Table 1) was confirmed by finding fragmented red cells on the peripheral smear, haemoglobin of $8.9 \mathrm{~g} / \mathrm{dl}$ which $12 \mathrm{hr}$ later had fallen to $5.9 \mathrm{~g} / \mathrm{dl}$; platelet count of $28 \times 10^{9} / 1$ and reticulocyte count of $20 \%$. Coagulation studies were grossly abnormal with a greatly prolonged thrombin clotting time, low fibrinogen titres and fibrinogen levels and raised levels of fibrin degradation products. Haemosiderinuria was present. The serum bilirubin level was $18 \mathrm{mmol} / \mathrm{l}$; SGOT $127 \mathrm{mmol} / \mathrm{l}$; SGPT 131 $\mathrm{mmol} / \mathrm{l}$; total protein $61 \mathrm{~g} / \mathrm{l}$; urea $4.8 \mathrm{mmol} / \mathrm{l}$. Coombs' test, auto-haemolysis, Ham test, DonathLandsteiner test, $\mathrm{Hb}$ electrophoresis and tests for circulating antibodies were negative. No evidence of infection was found. Cultures of blood, nose, throat, urine were negative. In view of the coagulation defect initial surgery was not possible and therefore 
TABLE 1. Serial values of $\mathbf{H b}$, platelets and reticulocyte counts, coagulation screening tests (prothrombin time, kaolin and thrombin clotting titres) fibrin degradation products together with urinary VMA levels. Details of therapy are included

\begin{tabular}{|c|c|c|c|c|c|c|c|c|c|c|c|}
\hline & & & & & & Day & & & & & \\
\hline & 2 & 4 & 7 & 14 & 18 & 23 & 30 & 42 & 65 & 68 & 75 \\
\hline $\mathrm{Hb} \mathrm{g} / \mathrm{dl}$ & $5 \cdot 9$ & $8 \cdot 9$ & $10 \cdot 8$ & $9 \cdot 5$ & $9 \cdot 3$ & & $9 \cdot 8$ & $10 \cdot 1$ & $7 \cdot 0$ & $6 \cdot 6$ & $10 \cdot 2$ \\
\hline Platelets $\times 10^{\circ} / 1$ & 76 & 5 & 67 & 61 & 157 & 445 & 250 & 475 & 35 & 35 & 90 \\
\hline Reticulocytes \% & 20 & $18 \cdot 2$ & $2 \cdot 6$ & $1 \cdot 4$ & & & & & 10 & 11 & 4 \\
\hline *Prothrombin time ratio & & $2 \cdot 0$ & $1 \cdot 7$ & $1 \cdot 7$ & $1 \cdot 3$ & $1 \cdot 0$ & $1 \cdot 1$ & 1.0 & $2 \cdot 2$ & 1.8 & $1 \cdot 4$ \\
\hline${ }^{*}$ Kaolin clotting titre ratio & & $1 \cdot 3$ & $1 \cdot 6$ & $1 \cdot 4$ & $1 \cdot 3$ & $1 \cdot 1$ & $1 \cdot 1$ & $1 \cdot 0$ & $1 \cdot 7$ & $1 \cdot 6$ & $1 \cdot 2$ \\
\hline *Thrombin clotting titre ratio & & $16 \cdot 0$ & $2 \cdot 2$ & 1.9 & $1 \cdot 6$ & $1 \cdot 6$ & $1 \cdot 2$ & $1 \cdot 1$ & $2 \cdot 8$ & $3 \cdot 1$ & $1 \cdot 4$ \\
\hline Fibrinogen titre $\mathrm{N} 1 / 32$ & & $1 / 2$ & $1 / 8$ & $1 / 32$ & $1 / 32$ & $1 / 16$ & $1 / 64$ & $1 / 64$ & $1 / 4$ & $1 / 8$ & $1 / 16$ \\
\hline Fibrinogen $\mathrm{mg} \%(2-4 \mathrm{~g} / \mathrm{l})$ & & 23 & 16 & & & & & & & & \\
\hline FDP $\mu \mathrm{g} / \mathrm{ml}(20)$ & $80-160$ & $80-160$ & $80-160$ & $10-40$ & $10-40$ & $10-40$ & $40-80$ & $10-40$ & $40-80$ & $10-40$ & $80-160$ \\
\hline $\begin{array}{l}\text { Urinary VMA mmol/mol } \\
\text { creatinine (N 20) }\end{array}$ & 151 & 154 & 152 & 175 & & 110 & & 61 & 146 & 225 & 226 \\
\hline \multicolumn{12}{|l|}{ Treatment } \\
\hline Vincristine (mg) & $0 \cdot 3$ & & $0 \cdot 3$ & $0 \cdot 3$ & & $0 \cdot 3$ & & $0 \cdot 3$ & $0 \cdot 3$ & & \\
\hline Cyclophosphamide (mg) & 62 & & 62 & 62 & & 62 & & 62 & 62 & & \\
\hline $\begin{array}{l}\text { Adriamycin (mg) } \\
\text { Hepatic radiotherapy } 50 \mathrm{rad} \text { in }\end{array}$ & & & & & & & & & 6.6 & & \\
\hline 7 fractions & & & & & & & & & & $50 \mathrm{rad}$ & \\
\hline Blood transfusion & $120 \mathrm{ml}$ & $120 \mathrm{ml}$ & & & & & & & & & \\
\hline
\end{tabular}

*Values given as ratio - patient/control.

cytotoxic chemotherapy was started using i.v. vincristine $(0.05 \mathrm{mg} / \mathrm{kg})$ and cyclophosphamide $(10 \mathrm{mg} / \mathrm{kg})$ at weekly intervals for the first 6 weeks. A blood transfusion $(120 \mathrm{ml})$ was given on days 1 and 3, no vitamin $\mathrm{K}$ was given. As can be seen from Table 1 a rapid improvement in the haemolytic anaemia and coagulation abnormality, and decrease in urinary VMA levels was associated with cytotoxic chemotherapy. The child became more content and fed better, skin nodules decreased in size but only minimal shrinkage of the abdominal girth and hepatomegaly was noted. On the 35th day, laparotomy was undertaken, a small primary in the right adrenal gland was removed. However, the liver was grossly enlarged owing to multiple metatases, metastases were also present in the para-aortic nodes. The histology of the adrenal tumour showed a haemorrhagic necrotic neuroblastoma. Following laparotomy the infant remained reasonably well for the next 30 days, although abdominal girth and hepatomegaly remained unchanged. Following this brief respite the signs of microangiopathic haemolytic anaemia and consumption coagulopathy recurred, together with an increase in abdominal tumour bulk, retro-orbital metastases and skin nodules. This deterioration was accompanied by an increase in urinary VMA.

Estimation of specific coagulation factors were done on the 65th and 75th day before and after hepatic irradiation (50 rad in 7 fractions). These factors were assayed by the following methods. Prothrombin (Factor II) was measured by the method of Koller, Leoliger and Duckert (1951) using commercially available reagents (A.H.S., U.K.
Ltd; Didcot, U.K.). Factor V was assayed by the method of Kapeller (1955) as described by Giddings, Shearn and Bloom (1975), factor VII as described by Garner and Conning (1970), factor VIII by the method of Pool and Robinson (1959) and factor XI by the method of Giddings (1971). Other quantitative assays were performed by one-stage techniques using substrate plasma samples obtained from patients congenitally deficient in the respective factor (Denson, 1966). The greatest reduction was seen in factors VII, IX, X, II and I, which changed from $64-88 \%, 36-120 \%, 36-80 \%, 21-38 \%, 1 / 4-1 / 16$ respectively, whereas factors $\mathrm{V}$ and VIII were 50 and $61 \%$ respectively (Table 2 ). Unfortunately none of

TABLE 2. Estimation of specific coagulation factors before and after hepatic irradiation (50 rad in 7 fractions) on 65 th and 75 th hospital day.

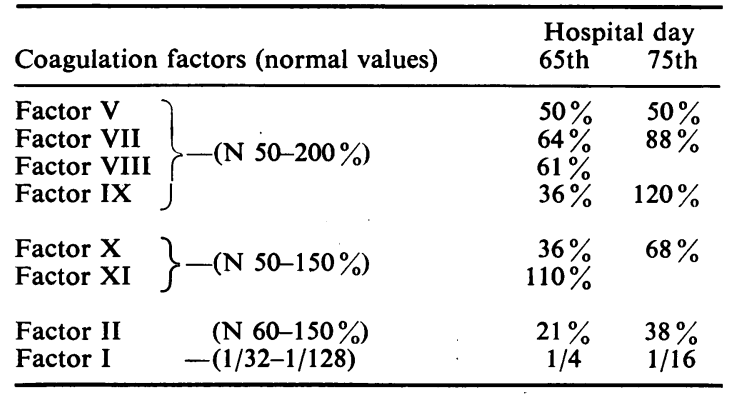

these factors had been measured initially but, as can be seen from Table 1, a response to cytotoxic drugs and radiotherapy was already taking place before day 
65 which might explain why factors V and VIII were not unduly low on the first day of estimation. Despite the improvement in coagulation the infant's overall condition deteriorated with increase in tumour bulk both intra-abdominally and retro-orbitally. Treatment was discontinued on the 75th day and he died 15 days later.

Post-mortem (within $12 \mathrm{hr}$ of death) revealed bilateral deposits in the region of both adrenals together with spread to local nodes. Massive hepatic deposits were present (weight of liver $680 \mathrm{~g}$ ). No extension to the spinal cord was found but a solitary metastasis in the right temporal bone was shown. Histology revealed no evidence of fibrin deposition within blood vessels.

\section{Discussion}

The evidence for disseminated intravascular coagulation in this case is strong, i.e. the low fibrinogen titres, thrombocytopenia, greatly prolonged thrombin clotting time, raised fibrin degradation products (FDP) levels and a micro-angiopathic haemolytic anaemia. The absence of any other cause of DIC except the tumour, and the good response haematologically lead one to consider that the coagulopathy was related to the tumour. Individual clotting factor assays were measured late in the course of the illness and could have been influenced by impaired hepatic synthesis because of the tumour or its treatment, i.e. hepatic irradiation.

The rapid improvement in the coagulation results following the initiation of chemotherapy is interesting. The case described by Faxelius et al. (1975) was treated with heparin and later cytotoxic drugs, only the anti-tumour therapy significantly affected the coagulation defect. Replacement coagulation factors were used in the other reported case with no reported benefit (McMillan et al., 1968). The present authors did not feel that the failure to detect fibrin deposition on the vascular endothelium at post-mortem necessarily excluded DIC, as lysis of fibrin can occur after death.

DIC in association with cancer is well known more often giving rise to haemorrhagic manifestations than thrombotic (Al-Mondhiry, 1975). In some cases the coagulopathy may be asymptomatic and only detected on investigation (Al-Mondhiry, 1975; Peck and Reiquam, 1973). Neuroblastoma is a common tumour in childhood and yet an excessive haemorrhagic tendency is not a feature in the child with relatively localized disease. Bleeding is usually associated with thrombocytopenia due to widespread marrow involvement but in some, hyperfibrinolysis has been the primary cause (Girolani, 1967). The haemorrhagic tendency, which was a dominant early symptom in the present case and in the 2 reported cases (a major cause of death in one), appeared to be due to the consumption coagulopathy which was reversible following specific anti-tumour therapy.

If consumption coagulopathy is truly a rare event in this tumour and not just due to failure of recognition, the similarities between the 2 other reported cases and the present case are interesting, as the clinical findings and course were alike, and at variance from well known predictive features of this tumour such as age and pattern of metastatic involvement. The age associated benefit is well recorded (Dargeon, 1962; de Lorimier, Bragg and Linden, 1969; d'Angio, Evans and Koop, 1971; Schwartz et al., 1974) and the higher incidence of asymptomatic neuroblastoma in situ in infants less than 3 months of age well documented (Beckwith and Perrin, 1963). Spontaneous regression of widespread metastatic disease is well known and more likely to occur in very young infants (Everson and Cole, 1966). Evans, d'Angio and Randolph (1971), in their staging classification, drew attention to the better prognosis of children with widespread metastases to liver, skin, and marrow but not to bone, and felt they should be considered separately in a $4 \mathrm{~S}$ group. The superior outlook in this group is now well recognized (d'Angio et al., 1971 Schwartz et al., 1974; Bond, 1976). In spite of the better clinical course run by children with $4 \mathbb{P}$ disease, it is interesting that the 6 patients recordef by Pepper (1901) were aged 1-8 weeks at diagnosis all had massive hepatic metastases (from bilateral adrenal tumours in 2, right adrenal in 2, left adrenal in one, other primary not found), and all died within a few weeks of diagnosis. All had extensively metastasised to the liver exclusively and so were stage $4 \mathrm{~S}$ cases. Post-mortem findings showed massive haemorrhagic tumour in the liver. There was no reference to a haemorrhagic tendency before death.

It is tempting to speculate that this very vascular tumour with vascular hepatic metastases invading the portal sinusoids of the liver, activates the coagulation system by thromboplastic material released from tumour tissues and/or destruction of the endothelium of the sinusoids by tumour invasion (Merskey et al., 1967; Peck and Reiquam, 1973; Sun et al., 1974; Al-Mondhiry, 1975). Perhaps the association of DIC in this tumour is not so rare as is suggested by the 3 cases reported, and that this may be present if looked for using the appropriate tests. Alternatively, this complication may be related to the predominant site of the metastases and the age of the patient. However, the clinical vagaries of this tumour are well known and perhaps an abnormality of the clotting mechanism may be present in only some of them. 


\section{Acknowledgments}

We would like to thank Mr John Giddings for the assays of the specific coagulation factors, Professor Bloom and Dr Tom Parry for haematological advice, and Dr Roger Seal for the histological evaluation.

\section{References}

AL-Mondhiry, H. (1975) Disseminated intravascular coagulation. Experience in a major cancer centre. Thrombosis et diathesis haemorrhagica, 34, 181.

BeCkwith, J.B. \& Perrin, E.V. (1963) In situ neuroblastoma. A contribution to the natural history of neural crest tumors. American Journal of Pathology, 43, 1089.

BoND, J.V. (1976) Neuroblastoma metastatic to the liver in infants. Archives of Disease in Childhood, 51, 879.

D'ANGio, G.J., Evans, A.E. \& Koop, C.E. (1971) Special pattern of widespread neuroblastoma with a favourable prognosis. Lancet, i, 1046.

DARgEON, H.W. (1962) Neuroblastoma. Journal of Pediatrics, $61,456$.

DE Lorimier, A.A., BragG, K.U. \& Linden, G. (1969) Neuroblastoma in childhood. American Journal of Diseases of Children, 118, 441.

Denson, K.W.E. (1966) Reagents and techniques. In: Treatment of Haemophilia and Other Coagulation Disorders. (Ed. by Biggs, R. \& Macfarlane, R.G.). Blackwell Scientific Publications, Oxford.

Evans, A.E., D'Angio, G.J. \& RandolPh, J. (1971) A proposed staging for children with neuroblastoma. Cancer, 27, 374.

EVERSON, T.C. \& Cole, W.H. (1966) Spontaneous Regression of Cancer. W. B. Saunders Co., Philadelphia.

Faxelius, G., Teger-Nilsson, A.C., Wilhelmsson, A. \& Astrom, L. (1975) Disseminated intravascular coagulation and congenital neuroblastoma. Acta paediatrica scandinavica, 64, 667.

GARNER, R. \& CoNNING, D.M. (1970) The assay of factor VII by means of a modified factor VII deficient dog plasma. British Journal of Haematology, 18, 57.

GidDINGs, J.C. (1971) Preparation and use of a new artificial system for a factor XI assay. Medical Laboratory Technology, 28, 284.

GiddingS, J.C., Shearn, S.A.M. \& Bloom, A.L. (1975) The immunological localisation of factor $V$ in human tissue. British Journal of Haematology, 29, 57.

GirolaNI, A. (1967) A coagulation study in patients with neuroblastoma. Tumori, 53, 49.

KAPELler, R. (1955) Das Verhalten von Factor im Serum unter normallen und pathologischen Bedingungen. Zeitschrift für klinische Medizin, 153, 103.

Koller, F., Leoliger, A. \& DUCKerT, F. (1951) Experiments on a new clotting factor (Factor VII). Acta haematologica, 6, 1.

McMillan, C.W., Gaundry, C.L. \& Holemans, R. (1968) Coagulation defects and metastatic neuroblastoma. Journal of Pediatrics, $72,347$.

Merskey, C., Johnson, A.J., Kleiner, G.L. \& Wohl, H. (1967) The defibrination syndrome: clinical features and laboratory diagnosis. British Journal of Haematology, 13, 528.

PeCK, S.D. \& Reiquam, C.W. (1973) Disseminated intravascular coagulation in cancer patients, supportive evidence. Cancer, 41, 114.

PEPPER, W. (1901) A study of congenital sarcoma of the liver and the supra renals. American Journal of Medical Science, 121, 287.

Pool, J.G. \& Robinson, J. (1959) Assay of plasma antihaemophilic globulin (AHG). British Journal of Haematology, 5, 17.

Schwartz, A.D., Dadash-Zadeh, M., Lee, H. \& Swaney, J.J. (1974) Spontaneous regression of disseminated neuroblastoma. Journal of Pediatrics, 85, 760.

Sun, N.C., BowIE, E.J.W., KAZMIER, F.J., EBEbACK, L.R. \& OWEN, C.A. (1974) Blood coagulation studies in patients with cancer. Proceedings. Mayo Clinic, 49, 636. 